Portland State University

PDXScholar

\title{
Effects of Certain Linguistic Parameters Upon the Responses of Preschool Subjects to Specific Dichotic Listening Tasks
}

Peggy J. Weber

Portland State University

Follow this and additional works at: https://pdxscholar.library.pdx.edu/open_access_etds

Part of the First and Second Language Acquisition Commons, and the Speech and Hearing Science Commons

Let us know how access to this document benefits you.

\section{Recommended Citation}

Weber, Peggy J., "Effects of Certain Linguistic Parameters Upon the Responses of Preschool Subjects to Specific Dichotic Listening Tasks" (1972). Dissertations and Theses. Paper 1568.

https://doi.org/10.15760/etd.1568

This Thesis is brought to you for free and open access. It has been accepted for inclusion in Dissertations and Theses by an authorized administrator of PDXScholar. Please contact us if we can make this document more accessible: pdxscholar@pdx.edu. 
AN ABSTRACT OF THE THESIS OF Peggy J. Weber for the Master of Science in Speech: Emphasis in Speech Pathology/Audiology presented Juiy $28,1972$.

Title: Effects of Certain Linguistic Parameters Upon The Responses of Preschool Subjects To Specific Dichotic Listening Tasks.

APPROVED BY MEMBERS. OF THE I'HESIS COMMITTEE:

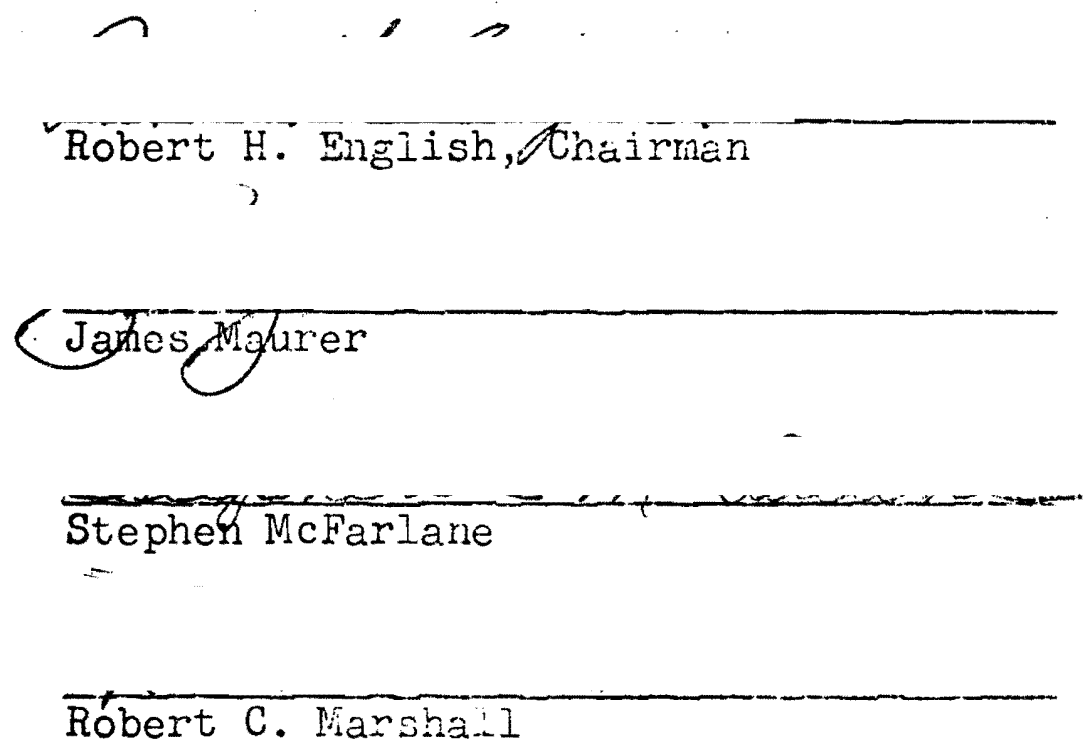

Listening, as a communication skill, is an essential factor in the normal language development of the child. Until recently, however, there has been very littje research conducted concerning the linguistic parareters that influence the ability to Iisten. Thus, this investigation mis designed to study the effects of two inguistic parameters, construction and semantic constraints on the verbal resporses of preschool children in a dichotic listening task. 
Fifteen children, between the ages of 5-3 to 6-8, were presented with four dichotic listening tasks consisting of 80 stimuli, ( 40 sentences and 40 pseudo-sentences). The children were asked to report the message delivered to their right ear.

The performance of the children was analyzed according to the F-Test and the Test of Least Significant Difference. The results showed that construction errors were the only statistically significant errors $(P<.05)$ among the six types of error types counted in the listening tasks.

There were fewer construction errors made when there was a meaningful message to report than when there was a nonmeaningful one. Although the semantic parameters were not statistically significant in this study, other investigations have demonstrated their influence on the report of subjects in a dichotic listening task. Therefore, a future research project should be conducted placing a greater emphasis on the sementic parameters.

Additionally, a three level listening hierarchy was fourd. It was based upon the number of construction errors that occurred among the four dichotic listening tasks. This writer feels that future research should pursue the question of an existing hierarchy among dichotic listening tasks. Such an investigation, however, should utilize a larger population than the population tested in this study. 


\title{
EFFECTS OF CERTAIN IINGUISTIO PARAMETERS UPON THE RESPONSES OF PRESCHOOL SUBJECTS \\ TO SPECIFIC DICHOTIC LISTENING TASKS
}

by

PEGGY J. WEBER

\begin{abstract}
A thesis submitted in partiai fulfillment of the requirements for the degree of

MASTER OF SCIENCE

in
\end{abstract}

SPEECH: FMPHASIS IN SPEECH PATHOLCGY/AUDIOLOGY

$$
\begin{gathered}
\text { Portland State University } \\
\qquad 972
\end{gathered}
$$


TO THE OFFICE OF GRADUATE STUDIES:

The members of the Committee approve the thesis of Peggy J. Weber presented July 28, 1972.

Robert H. English, 布. Ed., Chairman

Fobert C. Marshall, Ph.D.

Jandes Mayzert, Ph.D.

Steplen McFarlane, MST ' $v$

APPROVED:

Eobert W. Vogelsadg, Ėa.D, Hzad, Department of Speech 7 1

Datid T. Clark, Ph.D., Dean of Graduate Studies 
ACKNOWLEDGMENTS

The author wishes to express thanks to the following people with whom she worked to complete this thesis:

First, to Doctors Robert H. English, my chairman at Portland State University, and Robert C. Marshall, Chief of Speech Fathology, Veteran's Administration Hospital, who offered helpful suggestions during the preparation of this manuscript.

Secondly, to Steve McFarlane and Dr. James Maurer who participated as committee members.

Thirdly, to Larry Sawyer, Ted Clark and Stanley Nuffer of Portland State University and Gordon Frost of Tektronics who designed the organization for the necessary instrumentation.

Fourth, to Doctors Jack Hegreness and Dean Clarkson of the University of Oregon Medical School for their assistance in the statistical computation of the data.

Fifth, to Charlene White who edited and typed the thesis from its origin.

Sixth, to the parents and children of Lad's and Lassie's Preschool and Kindergarten who participated in the study.

find last, but not least, to Dr. Curtis Weiss of the University of Oregon Medical School from whom the idea for 
the thesis originated. 
TABLE OF CONTENTS

LIST OF TABLES . . . . . . . . . . . . . . . . . vi Chapter

I. INTRODUCTION AND STATEMENT OF PROBLEM. . . . . . . I Introduction . . . . . . . . . . . . . 1 Statement of Problem . . . . . . . . . 3 Questions to be Answered . . . . . . 3 Specific Terms Employed. . . . . . . 4

IT. A REVIEW OF THE IITERATURE . • • • . . . . . . . . 7

III. EXPERIMENTAL PROCEDURES. • . . . . . . . . . . . 14

Selection of Subjects. . . . . . . . . . 14 Screening of Subjects. . . . . . . . . 14 Description of Subjects. . . . . . . . . . . Instrumentation. . . . . . . . . . . . . . Tests. . . . . . . . . . . . . . . . . . .

Administration of Tests. . . . . . . . . . 18

Test Environment......... . . . . . . 8

Method . . . . . . . . . . . . . . . .

Special Scoring Criteria . . . . . . . . . . • •

IV. RESULTS AND DISCUSSION . . . . . . . . . . . 22

Results. . . . . . . . . . . . . . . 22

Total Treatments... . . . . . . . . 22

Type of Errors . . . . . . . . . . . . . . 4

Discussion of Results. . . . . . . . . . . 31

Left Ear - Pseudo-Sentence, Right Ear -.

Sentence . . . . . . . . . . . 31

Left Ear - Sentence, Right Ear -

Sentence ........... . . . . . . 33

Left Ear - Sentence, Right Ear -

Pseudo-Sentence. . . . . . . . 34

Left Ear - Pseudo-Sentence, Right Ear -

Pseudo-Sentence. . . . . . . . 35

V. SUMMARY, CONCLUSIONS AND IMPLICATIONS. • • • • . 38

Summary. • . • . . . . . . . . . . . . 38 
Chapter

Conclusions . . . . . . . . . . . 39

Implications. . . . . . . . . . . . 41

BIBLIOGRAPHY. • • • . • . . . . • . . . . . . 44

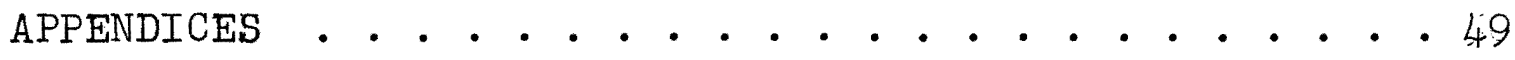

Appendix A - Survey form to determine Socio-

Economic level . . . . . . . 50

Appendix B - Instructions to Subjects . . . . . 51

Appendix C - Test Stimuli . . . . . . . . 52 


\section{LIST OF TABLES}

Table

I. Characteristics of the Sample . . . . . . 16

II. Total and mean number of errors for each child on each of the listening tasks and the Least Significant Difference between total errors and mean errors. . . . . . . . 23

III. Construction Errors - Total Errors and Means. . 25

IV. Semantic Errors - Total Errors and Means. . . 26

V. Don't Knows - Total Errors and Means. . . . 27

VI. Incomplete Errors - Total Errors and Means. . 28

VII. Combination Errors - Total Errors and Means . 29

VIII. Reversed Ear Reports - TotaI Errors and Means . 30 
CHAPTER I

\section{INTRODUCTION AND STATENENT OF PROBLEM}

\section{Introduction}

Human beings do not live in a world of social activity but are at the mercy of a particular language which has become the medium of expression for their society. It is quite an illusion to imagine that one adjusts to reality essentially without the use of language and that language is merely an incidental means of solving specific communications or reflections. The fact of the matter is that the real world to a large extent, is unconsciously built on the language habits of the group. We see, we hear, and otherwise experience largely as we do because the language of our community predispose certain choices of interpretation.

Vetter (1969)

The act of communication as described in the above quotation is a social act. In order for interpersonal communication to emerge within a group, however, a system of symbols known to everyone in the group must be established. A language system must be developed with which meaningful thoughts and ideas can be expressed.

Thoughts and ideas are social entities, learned from experience by individuals within the community. They do not begin, however, as thoughts or ideas. These socially learned behaviors are overlaid behaviors dependent upon the 
physical correlates that enable nerve impulses to reach the brain. Eventuelly in the process of communication, the physical phenomena of the brain become thoughts and ideas. Thus, "...communication demanding the selection, storage, and reproduction of material will occur only if the auditory mechanism of the brain operates normally," (Horowitz 1968).

Two of the more common modes of expressive communication are speaking and writing. These modes imply the application of listening and reading, the methods thrcugh which speaking and writing become liseful. According to Bordie (1970), speaking, writing, iistening, and reading form the basis for the language skills which humans possess. All four factors involve semantics, syntax, morphology, and vocabulary while sharing the aspects of intonation, stress, and body movements as adjuncts to the communication process. The-overall picture of language development depends on an interrelatedness of the four communication skills. Bordie (1970) points out, however, that each communication skill (listening, speaking, reading, writing) is distinct in its own right and can be defined as a separate entity. Because this investigator is concerned with oral language, listening will be the major focus of this paper. The skilis of reading have been vastiy researched and are closely 
related to listening but will only be discussed for the purposes of drawing comparisons between listening and reading (Fessenden 1955).

Listening has long been considered an essential factor in the communication situation. Its complexity, however, has only recently been viewed as an area of research. Thus, this writer, having a specific interest in preschool children, studied the listening skills of children in the preschool age group.

Statement of Problem

A review of the literature reveals a paucity of research dealing with the listening skills of children in the preschool and elementary years. The present investigation has been designed to study the effects of two parameters of linguistic redundancy: 1) construction and, 2) semantic constraints (Saunders 1970) as they relate to the performance of preschool children on various dichotic listening tasks.

\section{'Questions to be Answered}

The specific questions this investigation sought to answer include:

I) When given instructions to repeat a message delivered 
to the right ear, will the accuracy of the subject's responses be disturbed by the competing message delivered to the left ear?

2) Will an interfering, non-meaningful message in the left ear affect a subject's responses in the right ear more than a meaningful message delivered to the left ear?

3) Can the types of errors made by the preschool child to various dichotic listening tasks be meaningfully described in relation to the task in which they occurred?

\section{Specific Terms Employed}

There are numerous factors involved in a given listening task; therefore, it becomes necessary to establish definitions for specific operational terms which have been employed in this study. Other terms will be defined at the point of use.

Listening

Canfield (1958) defines listening "...as a complex of physical, psychological, and comprehensive functioning." It is the process of directing attention to oral language symbols, which are dependent upon auditory memory, in order that they may be recalled immediately after presentation. Attention

Attention, as defined by Anderson (1939), is "...the number of discrete elements grasped in a given amount of attention and organized into a unit for immediate (recall)." 
Dichotic Listening:

Dichotic listening (Nagafuchi 1970) is the "...simultaneous presentation of two (competing messages), " one to each ear.

Shadowing

Shadowing is the ability to repeat one of two messages while simultaneously listening to both messages (Cherry 1953).

Hierarchy

Hierarchy, as defined by The Rardom House Dictionary of the Eng]ish Language, "... is any system of order where certain entities are ranked one above the other." In a hierarchy of listening skills, like in language, there might be a system whereby certain combinations of verbal signal-to-noise ratios would be easier to listen to than others. Thus, a child might develop certain types of listening skills before he would learn other types. Linguistic Redundancy

Linguistic redundancy is defined "...as the moment a particular message has been selected, the choice of the message is limited by virtue of certain rules governing the relationship to the (previous message)" (Saunders 1970).

There are two types of constraints utilized in this study, construction and semantic constraints. 
Construction Constraints; Carroll (1964) defines construction constraints as a series of slots into which particular types of material may be fitted (adjective for adjective, noun for noun). The speaker is limited in ways in which he may combine constructs in order to convey a meaningful message by virtue of the English language. Certain words can only fill particular positions to be meaningful. For example, "The boy threw the ball," is a meaningful sentence. To substitute any other part of speech for the word "boy" would alter the meaning of the sentence completely.

Semantic Constraints; Semantic constraints, also defined by Carroll (1964), limit the choice of words (as opposed to parts of speech) that may be used to convey a particular meaning. For example, the incomplete phrase, "a cup of. , " can be completed only by a few words and still be meaningful. Thus, the words previous to the blank add a dimension of linguistic constraint and are used to meaningfully complete the sentence. 


\section{CHAPTER II}

\section{REVIEW OF THE LITERATURE}

In the previous chapter it was noted that listening, as a communication skill, has occupied the concern of scholars for sometime. Hence, literature dealing with the importance of Iistening abounds; however, empirical evidence concerned with listening as a complex human behavior is less prominent in the literature. As noted previously, there is even a greater paucity of research data relative to the nature of listening skills in preschool children.

In the present chapter this investigator has sought to review only that literature in the area of listening most closely associated with the problem under investigation. More specifically, primary consideration will be given to empirical evidence available regardless of the age level of subjects.

According to Witty and Sizemore (1968) studies drawing comparisons between visual and aural presentation of materials began in the late $1800^{\prime} \mathrm{s}$. One of the most relevant studies was conducted by A. C. Hermann (1912) who concluded that most people were of mixed imagery. He 
contended that visual material was remembered visually and auditory stimuli recalled aurally.

Until the early 1950's, when Brown (1957) coined the term "auding," listening was a much neglected area, however, Brown noted that auding, "...the process of hearing, listening to, recognizing, and comprehending the spoken language.. .," was thought to be the auditory correlate of reading. As a result, a series of studies were published the compared the listening and reading skills of young children. In studying "Auding as a Predictive Measure of Reading," Moe administered the auditory comprehension section of the Florida Reading Scale and the oral reading sub-test of the California Reading Test to 83 . first, second and third grade children and found a positive correlation between listening and reading among the first grade population and concluded that "auding ability" was a reliable predictor of reading ability at the first grade level, (Duker 1966).

Further studies were conducted by Deutsch (1964) and Bryne and Flynn (1970). They compared children of difierent socio-economic levels with respect to reading and auding abjiity. In the conclusions of these studies, it was stated that children from the lower economic level were retarded in both listening and reading skills when compared 
to a higher socio-economic group of children. The poorer readers of the higher socio-economic group, however, were deficient also in their listening skills.

More recently a considerable emphasis has been placed on the area of listening as a highly complex skill. Fessenden (1955) believes that listening progresses developmentally from the isolation and recognition of sound to the interpretation of sounds into meaningful units. Between these two extremes are the steps of integration, where information is mixed with past experience; and inspection, where relevant material is sorted from irrelevant material. Support for the premise that listening ability is a complex skill that emerges in a developmental or heirarchial fashion has been provided by investigations in which subjects have been asked to respond to dichotic listening tasks.

Broadbent (1954) speculating on the basis of memory through the use of dichotic listening tasks, concluded that dichotic listening was dependent upon a storage, as well as a perceptual system. In a study testing the verbal responses of adults to a dichotic listening task, Broadbent found that material in one ear is stored, while material in the other ear is immediately perceived and reported. Although Broadbent attributes the effects of the frequency and rate of aurally presented material to the perceptual- 
memory process, other authors have hypothesized additional factors accounting for responses to dichotic listening tasks (Emmerich 1965, Bartz 1967, Dodwell 1964, Treismann 1960).

Emmerich (1965) and Bartz (1967) concluded that the verbal response of a subject was dependent upon the meaningfulncss of the message. Bartz conducted a study of monosyllabic words used in a dichotic listening experiment. The college students participating in his study were asked to report what they had heard. Results of this investigation showed that fewer errors were made in the reports when the competing words formed a meaningful message. Bartz hypothesized, like Broadbent, the presence of a storage system which acted as a comparator for incoming stimuli. Meaning, according to Bartz, seems to be based on the ability of a person to compare current with past experiences; the comparative-storage system, as modeled by Bartiz, explains the responses of persons in a dichotic listening task and supports Fessenden's (1955) concept of listening development.

Dodwell (1964) and Treismann (1960) tested the effects of word familiarity, word redundancy, and word context in relation to the ability to select one of two competing messages. Dodwell (1964) determined that a person's 
CHAPTER III

\section{EXPERIMENTAL PROCEDURES}

\section{Selection of Subjects}

Twenty children, 12 boys and 8 girls, between the ages of 5.3 and 6.3 with a mean age of 6.1 were screened prior to the administration of the four dichotic listening tasks utilized in the investigation. All subjects were from the same kindergarten in Southwest Portland, Oregon, and came from upper middle class homes as rated by Warner's (1951) Index of Socio-economic Level. A Family Survey Form (See Apperidix A) provided the information to rate each family. At least one parent, if not both, in each household was a college graduate.

\section{Screening Procedures}

Subjects were further screened by utilizing the following instruments: a pure-tone audiological screening examination; the Peabody Picture Vocabulary Test, Form A; and the Larguage Mamual of the Crippled Children's Division, University of Oregon Medical School, Form B-Comprehension and Expression. 
Other influences upon the verbal responses to dichotic Iistening tasks have been studied by Bryden (1963) and Inglis (1967). They contended that the rate of presentation affects the subject's order of report if he is given the freedom to respond to either stimulus of the dichotic task. Additionally, Bryden (1963) feels that a faster rate of presentation ( 2 messages per second) forces the subject to report only material from one ear; usually the right ear. If the rate becomes slower, however, the subject's responses are altered from reporting the messages delivered only to one ear to reporting both competing messages as they are presented.

In further studies Bryden (1963) and Moray (1962) have defined a phenomenon called attempted ear order, the substitution of material for the given competing messages. Moray, in his study with children, contended that attempted ear order occurs most often when specific instructions are given by the examiner. He also stated that this phenomenon occurs more often in younger children than in older.

A number of other factors such as laterality, handedness, and cerebral dominance also seem to affect a person's response on a dichotic listening task. Kimura (1968) has concluded from her studies in dichotic listening that most people have a right ear dominance. Bryden (1963) also has 
conducted studies on right ear superiority in relation to cerebral dominance. In a case study of agenesis of the corpus callosum, he found that a person without a corpus callosum functioned as well as normals under dichotic listening conditions. Where part of the callosum was injured but still intact, unilateral suppression existed in a dichotic listening task. Bryden was unable to explain why this phenomenon occurred. Kimura (1968) hypothesized, however, that right ear dominance might be dependent on cortical competence and compensation rather than on the total absence of the corpus callosum.

In summary, there are many implications that can be drawn from a study of the factors that influence a subject's performance on dichotic listening tasks. Research, providing insight into the skills that make listening a complex entity, may prove to be very beneficial to programs for the poor reader and the hearing impaired person. 


\section{CHAPTER III}

\section{EXPERIMENTAL PROCEDURES}

\section{Selection of Subjects}

Twenty children, 12 boys and 8 girls, between the ages of 5.3 and 6.8 with a mean age of 6.1 were screened prior to the administration of the four dichotic listening tasks utilized in the investigation. All subjects were from the same kindergarten in Southwest Portland, Oregon, and came from upper middle class homes as rated by Warner's (1951) Index of Socio-economic Level. A Family Survey Form (See Appendix A) provided the information to rate each family. At least one parent, if not both, in each household was a college graduate.

\section{Screening Procedures}

Subjects were further screened by utilizing the following instruments: a pure-tone audiological screening examination; the Peabody Picture Vocabulary Test, Form A; and the Larguage Manual of the Crippled Children's Division, University of Oregon Medical School, Form B-Comprehension and Expression. 
For inclusion in the study, each subject had to meet the following criteria:

1. Respond to a pure-tone audiological screening examination at $15 \mathrm{~dB}$ (ISO) or better through the frequencies of $500-8000 \mathrm{cps}$.

2. Attain a mental age score corresponding to their chronological age as measured by the Peabody.

3. Attain age level performance for both comprehension and expression items from the CCD Language Manual.

4. Show no noticeable articulation errors by informal inspection.

\section{Description of Subjects}

Following the screening process, five children were eliminated from the study due to articulation errors. The fifteen remaining subjects ( 8 boys and 7 girls) had a mean CA of 6.1 and a mean MA of 8.0 (See Table I). AII subjects scored above their age level on the language evaluation with many either completing or showing a scattering of success through the 96 month level for both comprehension and expressive items.

\section{Instrumentation}

Recordings of test stimuli were made following Berlin's (1970) criterion. He contends that dichotic listening tasks are simultaneously matched only if they 
TABLE I

CHARACTERISTICS OF THE SAMPLE

\begin{tabular}{|c|c|c|c|}
\hline Subjects & Sex & 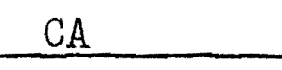 & Peabody MA \\
\hline 1 & $\mathrm{M}$ & $5-11$ & $6-10$ \\
\hline 2 & $F$ & $6-4$ & $8-1$ \\
\hline 3 & M & $6-4$ & $6-6$ \\
\hline 4 & M & $6-1$ & $9-5$ \\
\hline 5 & $F$ & $6-1$ & $7-8$ \\
\hline 6 & $F$ & $5-1$ & $7-8$ \\
\hline 7 & M & $5-8$ & $8-1$ \\
\hline 8 & M & $6-1$ & $9-2$ \\
\hline 9 & $F$ & $6-3$ & $7-3$ \\
\hline 10 & M & $6-4$ & $7-3$ \\
\hline 11 & $\mathrm{~F}$ & $5-6$ & $3-3$ \\
\hline 12 & M & $5-11$ & $8-7$ \\
\hline 13 & M & $6-8$ & $13-2$ \\
\hline 14 & $F$ & $5-3$ & $6-3$ \\
\hline 15 & $F$ & $5-10$ & $6-3$ \\
\hline TOTAL & $\begin{array}{l}8 \text { Males } \\
7 \text { Females }\end{array}$ & $\begin{array}{l}\text { Range } \\
5-3 \text { to } 6-8 \\
\bar{X} C A=6.1\end{array}$ & $\begin{array}{l}\text { Range } \\
6-3 \text { to } 13-2 \\
\bar{X} M A=8.0\end{array}$ \\
\hline
\end{tabular}


are within three milliseconds of each other.

All test stimuli were initially recorded on a Sony TC Stereophonic Taperecorder at $7 \frac{1}{2}$ inches per second. A relatively constant loudness level was maintained during the recording session by observing the $\mathrm{V}-\mathrm{U}$ meter on the recorder. A recording level of approximately 60-65 dB was maintained for all stimuli.

Twenty tapeloops were cut and individually placed on a Magnecord 135 Taperecorder. Each loop consisted of the two messages that would eventually be competing stimuli on the master tape. The tapeloops were manually adjusted until the two messages on them began within three milliseconds of each other. To insure the simultaneity of the messages, the Magnecord was connected to a Tektronics 564-B dual channel storage oscilliscope which visually portrayed the timing of the stimuli. When the stimuli were within three milliseconds of each other, they were recorded onto a master tape. The messages were then re-recorded on a final master tape to be used in testing. During the final recording, each set of stimuli was synchronized with serial numbers and a five second interval between the number and the beginning of the stimulus. A fifteen second interval also was maintained between each set of stimuli. 


\section{$\underline{\text { Tests }}$}

In order to form 20 sentences for this study (See Appendix B, All items numbered 1), a random sample of words was extracted from A Teacher's Book of 30,000 Words by Thorndike and Lorge (1944). Individual words were also taken from the same source and randomly ordered in groups of four to form 20 groups of pseudo-sentences (See Appendix B, All items numbered 2). These forty units were then recorded as has been previously described so that two competing messages could be played back with one message in each ear.

\section{Administration of Tests}

\section{Test Environment}

The testing of children took place in a quiet environment in the speech and hearing clinic at Portland State University. The room contained one table, three chairs and the testing equipment.

Method

Each child was given careful instructions as to the type of responses required of him (See Appendix C). Ear phones were placed over each ear and the recorder was turned on. An example of the type of stimuli was presented to the 
child and he was required to perform as he would in the actual test situation. The sample session was repeated once if the child did not understand the given instructions. During the actual test, twenty groups of words consisting of sentences and pseudo-sentences were randomly paired and presented simultaneously through the earphones to the child. Four of the messages were repeated four times during the test session to test for the general effect of redundancy on the subject's responses.

The competing messages were combined into four types of listening tasks. The four treatments were:

left ear - pseudo-sentence, right ear - sentence left ear - sentence, right ear - sentence left ear - sentence, right ear - pseudo-sentence left ear - pseudo-sentence, right ear - pseudo-sentence Intervals of fifteen seconds were maintained between stimuli in order to provide sufficient time for the child to respond to each stimulus heard. During the test situation, the examiner wrote what the child said in response to the taped stimuli for later analysis.

\section{Special Scoring Criteria}

Children's erroneous responses to the listening tasks were analyzed according to one of the following six error types.

Construction Errors: This type of error was identified 
by noting the total number of grammatical and syntactical changes made by the children in reporting the message delivered to the right ear.

Semantic Errors: Semantic errors were those in which the child changed a non-meaningful unit to a meaningful unit.

Combination Errors: The errors, for the purposes of this study, were those in which the child combined two competing messages to make a new work unit, i.e., left ear "family the happy was"; right ear - "bed gold is the"; response - "the family has a gold bed".

Incomplete Responses: This response was counted as an error because the child failed to complete the task.

Reversed Ear Order: This reponse was counted as an error because the child reported the message delivered to his left ear instead of the instructed ear of report (right ear).

Don't Knows: The response "don't know" was counted as an error because the child did not attempt to complete the given task.

Such an analysis made it possible for a child to have more than one error per response. For this reason, subjects' performance on the four dichotic listening tasks was studied with regard to the number and types of errors made by each 
made by each subject on each listening task instead of on a right-wrong basis. 
CHAPTER IV

\section{RESULTS AND DISCUSSION}

\section{$\underline{\text { Results }}$}

\section{Total Treatments}

Results of this investigation clearly suggest the existance of a hierarchy of listening ability in relation to performance on the four dichotic listening tasks. Table II gives the total number of errors for each subject on each of the dichotic listening tasks, the total number of errors for all subjects on each task and the mean number of errors per subject on all four tasks.

As can be seen in Table II, the range of errors for individual subjects on the LPS-RS task, was 0 to 11 with the mean number of errors per subject being 2.53. The error range for the LS-RS task was 1 to 9 with subjects averaging 4.27 errors. The LS-RPS and LPS-RPS tasks were the most difficult for the subjects of this study. The total number of errors for all subjects on the LS-RPS task ranged from 3 to 10 errors with a mean of 7.06. Errors for LPS-RPS ranged from 4 to 11 with a mean of 7.87 errors per child. 


\section{TABLE II}

Totals of Treatment Errors -- Consisting of:

a) Total errors each subject each task;

b) Total errors all subjects each task; and

c) Mean number of error - - per subject.

\begin{tabular}{ccccc}
\hline Subjects & LPS-RS & LS-RS & LS-RPS & LPS-RPS \\
\hline \hline 1 & 1 & 3 & 4 & 7 \\
2 & 1 & 3 & 4 & 6 \\
3 & 0 & 2 & 9 & 7 \\
4 & 4 & 8 & 10 & 11 \\
5 & 0 & 3 & 7 & 10 \\
6 & 5 & 6 & 9 & 10 \\
7 & 11 & 8 & 8 & 10 \\
8 & 6 & 6 & 10 & 8 \\
9 & 1 & 4 & 7 & 8 \\
10 & 1 & 3 & 9 & 10 \\
11 & 1 & 5 & 5 & 4 \\
12 & 0 & 1 & 3 & 4 \\
13 & 3 & 3 & 5 & 10 \\
14 & 2 & 1 & 8 & 10 \\
15 & 2 & 9 & 8 & 7.87 \\
\hline
\end{tabular}

KEY: LPS-RS = Left ear - Pseudo-Sentence, Right ear - Sentence

LS-RS = Left ear - Sentence, Right ear - Sentence

LS-RPS = Left ear - Sentence, Right ear - Pseudo-Sentence

IPS-RPS = Left ear - Pseudo-Sentence, Right ear - Pseudo-Sentence

These means had an $F$ value of 29.42 significant at the .05 level of confidence. For a significant difference to exist among the means, the Least Significant Difference would $\therefore$ have to equal or exceed 1.30 . 
To determine if significant differences existed among group treatment error means, the data were analyzed using the F-Test ( $\mathrm{Li}$ 1964). An $\mathrm{F}$ value of 29.42 with 59 degrees of freedom was obtained. This value, significant at the .05 level of confidence, suggests differences among the means. The Test of Least Significant Difference was calculated in order to determine if significant differences existed among the error means of the four listening tasks. The results of the LSD Test indicate that only two treatment error means, differing by more than 1.30, were significantly different at the .05 level of confidence. LSD results are summarized in Table II. In this case, any two means not underscored by the same line are statistically significant.

Types of Errors

Classification of the six error types have been described in Chapter III. Tables III through VIII show the number of errors per subject by type for each listening task.

Inspection of the tables reveals that construction errors (Table III) represent the most prevalent type of error noted in the four listening tasks. The range of subject errors for the IPS-RS was 1 to 5 with a mean of 


\section{TABLE III}

Totals of Construction Errors -- Consisting of:

a) Total errors each subject each task;

b) Total errors all subjects each task; and

c) Mean number of error -.- per subject.

\begin{tabular}{|c|c|c|c|c|}
\hline Subjects & LPS-RS & $I, S-R S$ & IS-RPS & LFS-RPS \\
\hline 1 & $i$ & 3 & $\mathrm{C}$ & 6 \\
\hline 2 & 1 & .1 & $I$ & 3 \\
\hline 3 & 0 & 2 & 6 & 3 \\
\hline 4 & 1 & 7 & 1 & 4 \\
\hline 5 & 0 & 3 & 3 & 5 \\
\hline 6 & 4 & 4 & 6 & 5 \\
\hline 7 & 5 & 6 & 6 & 5 \\
\hline 8 & 5 & 5 & 4 & 4 \\
\hline 9 & 1 & 3 & 3 & 3 \\
\hline 10 & 0 & 2 & 4 & 2 \\
\hline 11 & 1 & 2 & 2 & 3 \\
\hline 12 & 0 & 1 & 2 & 4 \\
\hline 13 & 3 & 3 & 4 & 4 \\
\hline 14 & $I$ & 1 & 6 & 3 \\
\hline 15 & ] & 5 & 3 & 4 \\
\hline $\begin{array}{l}\bar{T} \\
M\end{array}$ & $\begin{array}{l}24 \\
1.60\end{array}$ & $\begin{array}{l}38 \\
2.53\end{array}$ & $\begin{array}{l}51 \\
3.40\end{array}$ & $\begin{array}{l}58 \\
3.87\end{array}$ \\
\hline
\end{tabular}

These means had an $F$ value of 16.84 significant at the .05 level of confidence. For a significant difference to exist among the means, the Least Significant Difference would have to equal or exceed .69 . 


\section{TABLE IV}

Totals of Semantic Errors -- Consisting of:

a) Total errors each subject each task;

b) Total errors all subjects each task; and

c) Mean number of error -.. per subject.

\begin{tabular}{ccccc}
\hline Subjects & LPS-RS & LS-RS & LS-RPS & LPS-RPS \\
\hline \hline 1 & 0 & 0 & 0 & 1 \\
2 & 0 & 0 & 0 & 0 \\
3 & 0 & 0 & 1 & 1 \\
4 & 0 & 0 & 0 & 0 \\
5 & 0 & 0 & 1 & 1 \\
6 & 0 & 0 & 0 & 0 \\
7 & 0 & 0 & 0 & 0 \\
8 & 0 & 0 & 1 & 1 \\
9 & 0 & 0 & 4 & 3 \\
10 & 0 & 0 & 0 & 0 \\
11 & 0 & 0 & 0 & 0 \\
12 & 0 & 0 & 1 & 0 \\
13 & 0 & 0 & 0 & 0 \\
14 & 1 & 0 & 1 & 3 \\
15 & 1 & 0 & 1 & 1 \\
\hline \multicolumn{7}{c}{} & 0 & 0 & 10 & 0.80 \\
\hline
\end{tabular}

These means had an $F$ value of 2.36, non-significant at the .05 level of confidence. 
TABLE V

Totals of Don't Knows -- Consisting of:

a) Total errors each subject each task;

b) Total errors all subjects each task; and

c) Mean number of error.-- per subject.

\begin{tabular}{|c|c|c|c|c|}
\hline Subjects & LPS-RS & LS-RS & $\overline{\mathrm{LS}-\mathrm{RPS}}$ & LPS-RPS \\
\hline$I$ & 0 & 5 & 0 & 0 \\
\hline 2 & 0 & 2 & 3 & 3 \\
\hline 3 & 0 & 0 & 0 & 1 \\
\hline 4 & 3 & 7 & 1 & 6 \\
\hline 5 & 0 & 0 & 1 & 4 \\
\hline 6 & 1 & 0 & $i$ & 4 \\
\hline 7 & 0 & 0 & 0 & $\begin{array}{l}4 \\
0\end{array}$ \\
\hline 8 & 0 & 0 & 0 & 0 \\
\hline 9 & 0 & 0 & 0 & 2 \\
\hline 10 & 1 & 1 & 1 & $I$ \\
\hline 11 & 0 & 1 & 0 & 0 \\
\hline 12 & 0 & 0 & 0 & 0 \\
\hline 13 & 0 & 0 & 1 & 0 \\
\hline 14 & 0 & 0 & 0 & 0 \\
\hline 15 & 0 & 3 & 2 & 0 \\
\hline $\begin{array}{l}\text { TO } \\
\mathrm{Me}\end{array}$ & $\begin{array}{l}5 \\
0.33\end{array}$ & $\begin{array}{l}14 \\
0.93\end{array}$ & 10 & 2140 \\
\hline
\end{tabular}

These means had an $F$ value of 2.49 , non-significant at the .05 level of confidence. 


\section{TABLE VI}

Totals of Incomplete Errors -- Consisting of:

a) Total errors each subject each task;

b) Total errors all subjects each task; and

c) Mean number of error -.- per subject.

\begin{tabular}{|c|c|c|c|c|}
\hline Subiects & LPS-RS & $L S-R S$ & LS-RPS & LPS-RPS \\
\hline 1 & 0 & 0 & 0 & 0 \\
\hline 2 & 0 & 0 & 0 & 0 \\
\hline 3 & 0 & 2 & 0 & 2 \\
\hline 4 & 0 & 0 & 1 & 0 \\
\hline 5 & 0 & 0 & 0 & 0 \\
\hline 6 & 0 & 0 & 2 & 0 \\
\hline 7 & C & 0 & 0 & $I$ \\
\hline 8 & 0 & 0 & 1 & 0 \\
\hline 9 & 0 & 0 & 0 & 1 \\
\hline 10 & 0 & 0 & 3 & 1 \\
\hline 11 & 0 & 0 & 2 & 6 \\
\hline 12 & 0 & 0 & 0 & 0 \\
\hline 13 & 1 & 1 & 0 & 0 \\
\hline 14 & 0 & 0 & 1 & 0 \\
\hline \multirow[t]{3}{*}{15} & 0 & 0 & 2 & 2 \\
\hline & I & 3 & 12 & 13 \\
\hline & 0.07 & 0.20 & 0.80 & 0.87 \\
\hline
\end{tabular}

These means had an $F$ value of 3.47 significant at the .05 level of confidence. For a significant difference to exist, the Least Significant Difference had to equal or exceed .63. 


\section{TABLE VII}

Totals of Combination Errors -- Consisting of: ,

a) Total errors each subject each task;

b) Total errors all subjects each task; and

c) Mean number of error --- per subject.

\begin{tabular}{ccccc}
\hline Subjects & LPS-RS & LS-RS & LS-RPS & LPS-RPS \\
\hline \hline 1 & 0 & 0 & 2 & 0 \\
2 & 0 & 0 & 0 & 0 \\
3 & 0 & 0 & 0 & 0 \\
4 & 0 & 0 & 0 & 0 \\
5 & 0 & 0 & 0 & 0 \\
6 & 0 & 1 & 2 & 4 \\
7 & 5 & 2 & 1 & 5 \\
8 & 1 & 1 & 5 & 1 \\
9 & 0 & 0 & 0 & 1 \\
10 & 0 & 0 & 1 & 1 \\
11 & 0 & 0 & 1 & 0 \\
12 & 0 & 0 & 0 & 0 \\
13 & 0 & 0 & 0 & 0 \\
14 & 0 & 0 & 0 & 0 \\
15 & 0 & 1 & 0 & 1 \\
\hline
\end{tabular}

These means had an $F$ value of 1.28 , non-significant at the .05 level of confidence. 


\section{TABLE VIII}

Totals of Reversed Ear Reports -- Consisting of:

a) Total errors each subject each task;

b) Total errors all subjects each task; and

c) Mean number of error ... per subject.

\begin{tabular}{|c|c|c|c|c|}
\hline Subject & LPS-RS & LS-RS & LS-RPS & LPS-RPS \\
\hline$I$ & 0 & 0 & 2 & 0 \\
\hline$\overline{2}$ & 0 & 0 & $\tilde{0}$ & 0 \\
\hline 3 & 0 & c & 1 & 0 \\
\hline 4 & 0 & 0 & 8 & 1 \\
\hline 5 & 1 & 0 & 0 & 0 \\
\hline 6 & 0 & 0 & 0 & 0 \\
\hline 7 & 0 & 0 & 0 & 0 \\
\hline 8 & 0 & 0 & 0 & 0 \\
\hline 9 & 0 & 0 & 0 & 0 \\
\hline 10 & 0 & 0 & 0 & 0 \\
\hline 11 & 0 & 0 & 0 & 0 \\
\hline 12 & 0 & 0 & 0 & 0 \\
\hline 13 & 0 & 0 & 0 & 0 \\
\hline 14 & 0 & 0 & 0 & 0 \\
\hline 15 & 0 & 0 & 0 & 0 \\
\hline TOTALS & $\bar{l}$ & 0 & 11 & $I$ \\
\hline Means & .07 & 0 & .73 & .07 \\
\hline
\end{tabular}

These means had an $F$ value of 1.90 , non-significant at the .05 level of confidence. 
1.60. For the LS-RS and LS-RPS tasks, the errors range from 1 to 6 errors and 1 to 7 errors respectively with a mean of 2.53 for the former task and 3.40 for the latter. On the LPS-RPS task, the error range was 2 to: 5 with a mean of 3.87 per subject. The completed $F$ value of 16.84 ( $d F=$ 59) was significant at the .05 level suggesting differences between construction error means for the four listening tasks. The ISD Test, to be significantly different, would have to be equal or exceed .69. In this case, all means except the LS-RPS and LPS-RPS treatments were statistically different (See Table III).

Computed $F$ values testing the difference between other error types (semantic, don't know, incomplete, combination and reversed ear) in the listening tasks were not significant. This writer feels, however, that if the population were increased certain trends (See Tables IV, V, VI, VII, VIII) might develop which would be of value for future research.

\section{Discussion}

Based upon results obtained from the performance of subjects in this study, the number of reported errors seemed to be influenced by the type of listening task to which the child was responding. In support of Brown (1957) this 
writer feels that these results may indicate a hierarchy of listening skills based on the given dichotic tasks. In this study it seemed that the children found certain combinations of verbal signal-to-noise units easier to repeat correctly than other combinations.

Left Ear - Pseudo-Sentence, Right Ear - Sentence

Of the four types of dichotic listening tasks, subjects made significantly fewer total and construction errors on the LPS-RS combination. Examination of the results, in comparison with the subjects' performance on the LS-RS task, reveals that the subjects had significantly greater success in reporting meaningful messages delivered to the right ear, the ear in which the subjects were asked to listen, when the competing message in the left ear was nonmeaningful. These findings tend to support those of other investigators (Treismann 1960, Miller and Selfridge 1950, Dodwell 1954) who have utilized both older subjects and shorter messages. They concluded that word familiarity, word redundancy and sentence context tended to enhance the intelligibility of language and influenced the order of report in a dichotic listening task.

Additionally, Menyuk (1963), Ossler (1969) and Saunders (1.970) point out the importance of syntax in auditory 
recall. In the present study the significantly smaller number of construction errors when the task stimulus was meaningful (LPS-RS Combination) in comparison with the number of construction errors when the test stimulus was non-meaningful (LS-RPS. Combination) suggests that the syntactical structure of the reported message affects the child's ability to respond correctly. This finding tends to support Menyuk's emphasis of syntactical structure in relation to the correctness of verbal imitation.

In summary, the significant factor in this task would tend to be the possible influence of syntactical structure. Although the semantic parameter was not statistically significant, there was a trend demonstrating the influence of semantics. Further, the lack of syntactic and semantic structure to the left ear might have influenced the success of reporting the message delivered to the right ear.

\section{Left Ear - Sentence, Right Ear - Sentence}

Following the LPS-RS, the subjects made fewest errors on the LS-RS task. The total error mean for the LS-RS task differed significantly from every other error mean. The position of this task within the listening hierarchy can be partially explained from the conclusions of Peters (1954) and Webster and Thompson (1953) who agreed the more similar 
messages were in a dichotic listening task, the lower the relative efficiency of the one to be reported.

Competing messages of the LS-RS combination provide both grammatical and contextual familiarity and may, therefore, make the message of the right ear more difficult to decipher from the left ear by confusing the subject.

Left Ear - Sentence, Right Ear - Pseudo-Sentence

This treatment, significantly more difficult from the previous two tasks (See Table II), was not significantly different from the LPS-RPS treatment (See Table II). A complicating factor in the sentence task seemed to be that the interfering message contained both grammatical and contextual cues, while the message in the ear to be reported contained neither.

Results from Spreen and Boucher's (1970, p. 45) investigation provide a possible clarification of these findings. They state, "Right ear superiority is strictly a language related phenomenon and decreases as some of the normal characteristics of speech are removed."

By way of summary, applying Spreen and Boucher's concept to the present task, one can say the message to the right ear containing no linguistic patterns was dominated by the grammatical familiarity of the message to the left 
ear. It would appear that the structural entities of the sentences to the left ear overruled right ear dominance due to the lack of speech-like characteristics of the messages delivered to the right ear.

Additionally, it is to be noted in Table VIII, that there were more reversed ear reports for the LS-RPS task than for the other three tasks. Although this finding was not statistically significant, this writer feels that if the population were to be increased that it is possible a trend might develop in which linguistic patterning would act as a possible disorganizing factor to the message being reported.

Left Ear - Pseudo-Sentence, Right Ear - Pseudo-Sentence Group error means for the LPS-RPS task did not differ significantly from the LS-RPS task but did differ statistically from the LPS-RS and LS-RS listening tasks. It is possible that the lack of grammatical structure in the LPS-RPS combinations tended to interfere with the type of messages reported by each child. In this task, it was found that a number of the children ( $40 \%$ ) combined the two messages to create their own linguistic patternings from the words presented (See Table VII).

The fact that the LPS-RPS task proved to be the most 
difficult, is compatible with the findings of other researchers (Treismarn 1950, Miller and Selfridge 1950, Dodwell $1964)$.

These findings would seem to militate against the right ear dominance theory as stated by Kimura (1958). The fact that the concept of right ear dominance was supported only when the responses to be reported were meaningful (LPS-RS Combinations) suggests perhaps that right ear dominance may play only a secondary role in listening ability after the child has mastered the syntactical aspects of the language. Another possibility is that right ear superiority exists only for meaningful simuli. Further study of children's dichotic listening performance comparing right and left ear responses would seem warranted.

The parameters that made a message meaningful are very difficult to separate from each other entirely. Therefore, this investigator, while attempting to separate syntactic and semantic factors within this study, realizes the two are independent. A possible reason why there were no significant semantic errors made by the subjects is that the design of the study did not lend itself for true separation of syntactic and semantic parameters. In conclusion, therefore, other studies placing more emphasis on 
semantic redundancy (Carroll 1969) should be designed. 


\begin{abstract}
CHAPTER V
SUMMARY, CONCLUSIONS AND IMPLICATIONS
\end{abstract}

Summary of the Study

Listening as a complex, basic, communication ski.ll has only recently been considered an area of research. Furthermore, most of the listening studies have utilized adult. subjects leaving a paucity of information concerning the listening skills of preschool children. Therefore, this investigator sought to study the effects of two linguistic parameters, construction and semantic constraints, on the responses of young children presented with dichotic listening tasks. The following questions were asked:

1) When given instructions to repeat a message delivered to the right ear, will the accuracy of the subject's responses be disturbed?

2) Will an interfering, non-meaningful message in the left ear affect a subject's responses in the right ear more than a meaningful message delivered to the left ear?

3) Can the type of errors made by the preschool child to various dichotic listening tasks be meaningfully described in relation to the task in which they occurred?

The subjects, 7 girls and 8 boys, ranged in age from 
5-3 to 6-8. They were all from a Southwest Portland kindergarten and from families in which on parent, if not both, was a college graduate. Prior to the actual listening task each child was given an audiological examination, a Peabody Picture Vocabulary Test and portions of the Language Manual from the Crippled Children's Division of the University of Oregon Medical School. All children falling within the normal chronological and mental limits for their age level were chosen as subjects for this present study.

The F-Test and the Test of Least Significant Difference were used to statistically analyze the reported performance of the children on the listening tasks. Of the six error types possible, construction errors were the only significant error type according to the analysis. There were significantly fewer construction errors in relation to the other errors noted in the study. Although semantic factors of our language have been proven to affect auditory racall (Treismann 1960, Miller and Selfridge 1950, Dodwell 1964) they were not a significant finding in this study.

\section{Conclusions of the Study}

First, the questions posed by this investigation were answered in the following manner: 
1) Preschool children, when asked to report a meaningful message delivered to the right ear with a non-meaningful message delivered to the left ear, were able to successfully complete the given task with fewer number of errors ( $\mathrm{P}<$ $.05)$.

2) Preschool children had significantly greater difficulty in reporting a non-meaningful message delivered to the right ear regardless of the meaningfulness of the competing message $(P<.05)$.

3) Construction errors were found to be more prevalent in the responses of preschocl children when the message of report was a non-meaningful unit $(P<.05)$.

Second, it was found that syntactical and grammatical structure influenced the correctness of response more significantiy than the semantic parameter. Although other studies report a strong positive influence of the semantic aspect (Treismann 1960, Miller and Selfridge 1950, and Dodwell 1964) it did not contribute significantly to the accuracy of reporting in the present investigation.

Third, an additional factor resulting from this investigation was the identification of a three-level hierarchy. This hierarchy was noted when examining the number of construction errors found among the reports of subjects on the four dichotic listening tasks. The hierarchy in ascending order of difficulty is as follows:

1. Left ear - pseudo-sentence Right ear - sentence

2. Left ear - sentence Right ear - sentence 
3. Left ear - sentence
Right ear - pseudo-sentence

4. Left ear - pseudo-sentence (Not statistically Right ear - pseudo-sentence different although the LS-RPS task had a slightly lower mean than the LPS-RPS task)

Fourth, this investigation raises some questions concerning the theory of right ear dominance. Although Kimura (1968) has researched the dominance field the dominance field thoroughly, the dominance theory is widely disputed (Penfield 1934). Based upon the results of the present investigation, however, one cannot deny the possibility of right ear superirity.

The affects of linguistic parameters on right ear dominance, however, (specifically syntactical factors) can be noted from this study. The presence of syntactical factors in the message delivered to the right ear seemed to enhance the accuracy of the report from the child. If the message to be reported from the right ear lacked syntax, however, the subject had difficulty in recalling it accurateIy. Thus, syntax, according to the present investigation, affects right ear dominance.

\section{Implications of the Study}


possibilities of future research in the area of dichotic listening. First, since other researchers (Treismann 1950, Miller and Selfridge 1950, and Dodwell 1964) have concluded that the semantic parameter is a significant factor in the process of auditory recall, a study similar to the one just completed might be conducted emphasizing the semantic more than the syntactic aspect of our language.

Second, testing a larger population of preschoolers on the same tasks that were presented in this investigation might yield more trends and significant facts concerning parameters other than syntax.

Third, because most of the researchers comparing listening and reading have found a positive correlation between them, this investigator feels that emphasis on auditory skills within the preschool setting would alleviate some of the reading failures in the primary grades. A dichotic listening program based on a hierarchy of listening skills might be useful in refining a child's auditory attention, discrimination, and recall ability prior to the time he learns to read.

Lastly, dichotic listening might enhance the listening skills of hearing impaired children. According to Pollack $(1970)$ and Saunders (1970), the existing auditory programs leave much to be desired. Auditory training program often 
teach the hard of hearing person all the listening skills except those necessary for the awareness and comprehension of speech. Pollack and Saunders both suggest a more intensive auditory program which would familiarize the hearing impaired person with the linguistic parameters of speech. The process of developing listening skjlls in a normal hearing child should be specifically taught to a hearing impaired child. After learning the preliminary steps of listening development, a child should begin an auditory training program of dichotic listening to refine his auditory skills in relation to speech.

Thus, this investigator feels that the results of the current study can be most beneficial in three ways: 1) Planning listening programs for children in the regular classroom, 2) Planning listening programs for the hearing impaired person, and 3) Providing insight into the development of linguistic parameters in the preschocl child. 
SELECTED BIBLIOGRAPHY

References Cited

Anderson, Virgil. "Auditory Memory Span as Tested by Speech Sounds," American Journal of Psychology, Vol. 52, No. I, pp. 95-99, 1939.

Bordie, John. "Language Tests and Linguistically Different Learners - The Sad State of the Art," Elementary

English, Vol. 47, pp. 814-828, October, 1970.

Broadbent, Donald. "Role of Auditory Localization in Atten-

- tion and Memory," Journal of Experimental Psychology,

Vol. 47, No. 3, pp. 191-196, March, 1954.

Brown, Donald. "What is the Basic Language Skil.1?", ETC, Vol. 114, pp. 103-118, 1957.

Canfield, Robert. "Approaches to Listening Improvement," Elementary English, Vol. XXXV, No. 8, p. 525, JanuaryDecember, 1968.

Dodwell, C.: "Some Factors Affecting the Hearing of Words Presented Dichotically," Canadian Journal of Psychol-ogy, Vol. 18, No. 1., pp. 72-91, 1964.

Horowitz, Milton. "Listening and Reading Organizational Frocesses Underlying the Difference Between Listening and Reading as a Function of Material," Journal of Communication, Vol. 18, pp. 37-46, June, 1968.

Kimura, Doreen. "Cerebral Dominance and the Perception of Verbal Stimuli," Canadian Journal of Psychology, pp. 166-171, 1951.

Miller, George and Selfridge, Jennifer. "Verbal Context and the Recall of Meaningful Material," American Journal of Psychology, Vol. 53, No. 2, pp. 89-96, April, 1950. 
Moray, Mary. "Direct Measurement of Listening of Hearing Impaired Children," Journal of Speech and Hearing Research, pp. 65-74, March, 1970.

Nagafuchi. "Development of Dichotic and Monaural Hearing in Young Children," Acta Oto Laryngology, Vol. 56, p. I, February, 1970 .

Ossler, Harry; Wang, Marilyn, and Zaid, Lorida. "The Young Child's Ability to Imitate and Comprehend Speech: A Comparison of Two Subcultural Groups," Child Development, Vol. 40, pp. 14-19, December, 1969.

Pollack, Doreen. Educational Audiology for the Infant, 1971.

Saunders, Derek. Aural Rehabilitation, Prentice Hall, New Jersey, 1971.

Spreen and Boucher. "Effects of Low Pass Filtering on Ear Asymmetry in Dichotic Listening and Some Uncontrolled Error Sources," Journal of Auditory Research, pp. 4551, January, 1970.

Thorndike and Lorge. The Teacher's World Book of 30,000 Words, Teacher's College, Columbia University, 1944.

Treismann, Anne. "Contextual Cues in Selective Listening," Quarterly Journal of Experimental Psychology, Vol. VXII, No. 4, pp 42-47, November, 1960.

Vetter, Harold. Language Behavior and Psychopathology, Rand McNaliy Company, Chicago, Ill., 1969.

Witty, Paul and Sizemore, Robert. "Studies in Listening Part I: The Relative Value of Oral and Visual Presentations," Elementary English, Vol. VXXXV, p. 538, January-December, 1958 .

\section{Ref'erences Used But Not Cited}

Bakan, Paul. "Some Reflections of Listening Behavior," Journal of Communication, Autumn, pp. 108-112, 1956.

Bereiter, C. and Englemann, S. Teaching Disadvantaged 
Children in the Preschool, Prentice Hall, New Jersey, 1966.

Bernstein, J. Andrew and Schwebel, Andrew J. "The Effects of Impulsity on the Performance of Lower Socio-economic Children, Four WISC Sub-Tests," American Journal of Orthopsychiatry, Vol. 40, No. 1, pp. 629-636, July, 1970.

Berry, Lillian and Luterman, Asher Bar. "The Diagnostic Significance for Language Impaired Children," Journal of Speech and Hearing Disorders, Vol. 36, No. 1, p. 29, February, 1971.

Brotsky, Suellen. "Auditory Figure Ground Perception in the Neurologically Impaired," Journal of Auditory Research, Vol. 10, pp. 5-10, January, 1970.

Bryden, M. P. "Ear Preference in Auditory Perception," Journal of Experimental Psychology, Vol. 65, pp. 103$105,1963$.

Broadbent, Donald. "Attention and the Perception of Sound," Scientific America, April, 1942.

Broadbent, Donald. Perception and Communication, Pergamon Press, New York, 1958.

Brown, Kenneth. "Speech and Listening Textbooks in the Language Arts," Elementary English, pp. 366-372, April, 1967.

Carroll, J. B. Language and Thought, Englewood Cliffs, Prentice Hall, New Jersey, 1964.

Carrow, Sister Mary. "The Development of Auditory Comprerension in Children, "Journal of Speech and Hearing Disorders, May, 1968.

Clifton, Charles, Jr. and Bogartz, Richard. "Selective Attention During Dichotic Listening by Preschool Children," Journal of Experimental Psychology, Vol. 6, po. $483-491,1968$.

Curry, Fredrick and Stein, Laszlo K. "Childhood Auditory Agnosia," Journal of Speech and Hearing Disorders, 1968. 
Duker, Sam. Listening Readings, Scarecrow Press, New York, 1966.

Fessenden, Seth. "Levels of Reading - A Theory," Education, Vol. 75, pp. 288-291, 1955.

Giffner, Donna S. and Hochberg, Irving. "Ear Laterality Performance of Children from Low and Middle SocioEconomic Levels on a Verbal Dichotic Listening Task," Cortex, Vol. 7, pp. 101-107, June, 1971.

Hardy, William. "Human Communication Ordered and Disordered," The Volta Review, pp. 354-362, September, 1962.

Inglis, Sykes. "Dichotic Listening and Cerebral Dominance," Acta Dto Laryngology, Vol. 60, pp. 231-237, 1965.

Inglis, Sykes. "Some Sources of Variation in Dichotic Listening Performance in Children," Journal of Experimental Child Psychology, Vol. 5, pp. 480-488, $196 \%$

James, E. William; Mefferd, Ray J. and Willand, Betty A., "Repetitive Psychometric Measures: Digit Span," Psychological Reports, Vol. 8, pp. 3-10, 1966.

Kimura, Doreen. "Functional Asymmetry in the Brain," Cortex, Vol. 3, pp. 163-178, 1967.

Li, Jerome C. R. Statistical Inference, Library of Congress, 1964 .

Liberman. "Results on Research of Speech Perception," Journal of Acoustic Society of America, Vol. 29, No. I, pp. 49-61, January, 1957.

Liberman, et. al. "Ferception of the Speech Code," Psychological Review, Vol. 74, No. 6, pp. 431-461, 1967.

McGrady, Harold J. and Olson, Donald A. "Visual and Auditory Learning Processes in Normal Children with Specific Learning Disabilities," Exceptional Children, pp. 7276, April, 1970.

McNeille, D. "Catagorized Parts of Speech Basic to Syntax The Capacity for Language Acquisition, "Volta Review, Vol. $68, \mathrm{pp} .17-36,1966$. 
Menyuk, Faula. "Syntactic Structures in the Language of Children," Child Development, Vol. 34, pp. 407-422, 1963.

Metraux, Ruth Watt. "Auditory Memory Span for Speech Sounds of Speech Defective Children Compared with Normal Children," Journal of Speech and Hearing Disorders, Vol. 7, No. 1, pp. 33-37, March, 1942.

Mira, Mary. "Direct Measurement of Listening of Hearing Impaired Children," Journal of Speech and Hearing Research, pp. 65-74, March, 1970.

Moray, Neville. "Broadbent's Filter Theory "Postulate $\mathrm{H}$ and the Problem of Switching Time', "Journal of Experimental Psychology, Vol. 12, pp. 214-220, 1950.

Newsom, Elizabeth. "Visual and Conceptual Discrimination: The Background of Reading," Speech Pathology and Therapy, Vol 5, pp. 3-9, April, 1962.

Peters, W. J. "Competirg Messages - The Effect of Interfering Messages Upon the Reception of Primary Messages," U.S.N. Bureau of Aviation; Report No. 27, 1954.

Scott, Keith and Urboro, Richard. "Digit Span, Practice and Dichotic Listening Performance in the Mentally Retarded," Journal of Experimental Psychology, Vol. 8, No. 3, pp. 432-449, December, 1969.

Spellacy, J. "Lateral Preferences in the Identification of Patterned Speech," Journal of Acoustic Society of America, pp. 59-62, 1970.

Renfrew, C. "The Use of Oral Reading in Speech Therapy," Speech Pathology and. Therapy, pp. 16-20, April, 1962.

Warner, W. Social Class in America, Harper, Torchbook, 1960.

Wardbough, Ronald. "A Linguist Looks at Phonetics," Elementary English, pp. 11-15, January, 1971.

Webster, J.C. and Thomspon, F.A. "Responding to both of Two Over lapping Messages"; Journal of Acoustical Society, Vol. 26, pp. 396-4.02, 1954 .

Witkin, Ruth. "Auditory Perception and the Implications for Language Development," Journal of Research and Development in Education, Vol. 3, No. 1, pp. 105-112, 1969. 
APPENDICES 


\section{APPENDIX A}

FAMIIY S U R V E Y

Child's birthdate Sex

Father's Age Occupation

Highest Grade Completed Gross Monthly Income $\$$

Mother's Age___ Occupation

Highest Grade Completed Gross Monthly Income $\$$

OTHER SIBLINGS:

$\underline{\text { Sex }}$ Birthdate Birthplace Grade

1.

$\underline{2 .}$

3.

4.

5.

Others in Household: (Dependent upon or contributing to Family Income)

Relationship Age

1.

$\underline{2}$.

3.

4. 
Sample Stimuli:

\section{TEST STIMULI}

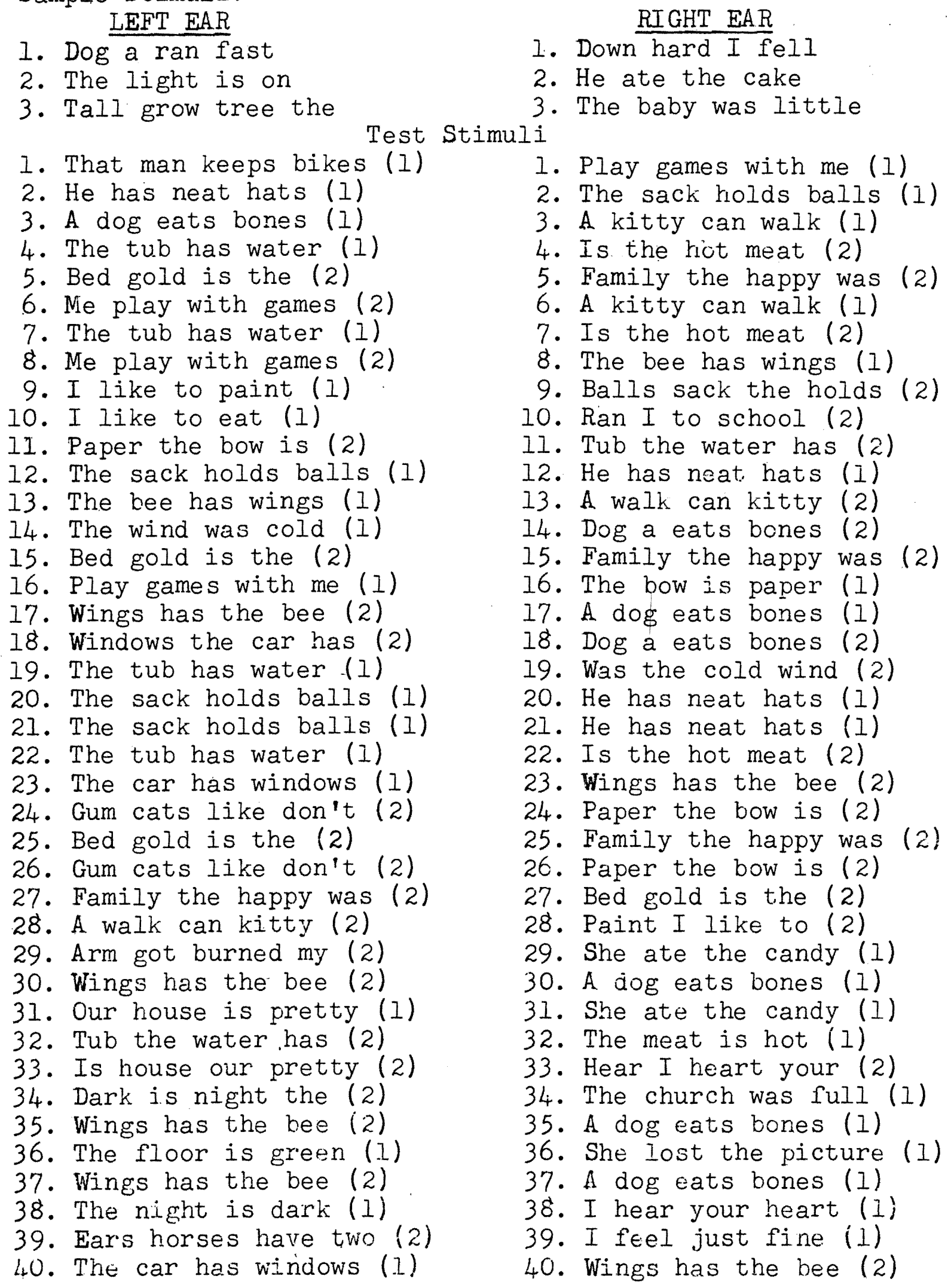




\section{INSTRUCTIONS TO CHILD}

Listen carefully. You will hear two sets of words, one in each ear. I want you to listen only to the group of words entering the right ear. This is the ear by your lollipop. After the voice stops saying the words, I want you to repeat exactly what you heard. Let's practice.

\section{TRIALS :}

\section{LEFT EAR}

The light is on (I)

Cow the brown is (2)

Down hard I fell (2) $\underline{\text { RIGHT. EAR }}$

Cake you ate the (2)

I want the car (I)

Ran school to I (2)

Training sessions will be repeated once if the child does not grasp the task the first time. 